\title{
Design and Development of Low Temperature Community Solar Dryer for Oily and Hard Edible Produces
}

\author{
Shruti Kumari ${ }^{1}$, Renu Kumari ${ }^{2}$, Shilpa Choudhary ${ }^{3}$, Sanjay Kumar ${ }^{4, *}$ \\ ${ }^{1}$ Department of Zoology, Lalit Narayan Mithla University, Darbhanga, Bihar, India \\ ${ }^{2}$ Department of Home Science, B. R. Ambedkar Bihar University, Muzaffarpur, Bihar, India \\ ${ }^{3}$ Department of Education, L.N.T. College, Bhagwanpur, Muzaffarpur, Bihar, India \\ ${ }^{4}$ Department of Physics, B. R. Ambedkar Bihar University, Muzaffarpur, Bihar, India \\ Corresponding email: prof.kumars@gmail.com
}

\begin{abstract}
:
Horticulture produce have very high-water content, sometimes more than $90 \%$ by volume. Several of them are oily and hard. These horticulture produce have very high count of free radicals and are medicinal in nature. Usually, these are grown in scattered places in rural areas on sidelines of regular agriculture, far from the market place. Their price slumps during seasons and increase exponentially after it, due to short lifetime and absence of good transportation network, cost-effective proper preservation technology as well as specialized transportation vehicles. In this paper, Small state of the art family size solar dryer of $5 \mathrm{~kg}$ per day is designed to dry these produces in a single day and validated in real time experiments. The dryer is capable of maintaining desired temperature range to extended period even after sunshine, with the help of High Heat Capacity Material and Phase Change Material. Humidity removal mechanism is also introduced to reduce drying time by at least two hours.
\end{abstract}

Keywords: Solar Dryer, Humidity Control Mechanism, Temperature Control, Community Drier

\section{Introduction}

Developmental plans and economic activities are often influenced by demographic changes. Regional imbalances, therefore, has been increasing since industrial revolution. However, global climatic changes and over exploitation of natural resources have made it mandatory for planners to create conditions of sustainable development in remote areas, degraded lands and tough terrains, so as to reduce if not stop migration of population in search of livelihood to urban slums [1]. Creating alternative modes of livelihood and economic activities in rural and arid areas deserve utmost attention since people residing there have preserved eco-diversity and ecosystem - a precious source of scientific knowledge in coming years. Besides, migrants from these areas find it too hard to assimilate into tough and competitive lifestyle of urban areas. India is second largest producer of fruits and vegetable. During 2014-15 India produced 86.602 million metric tonnes of fruits and 169.478 million metric tonnes of vegetables. The area under cultivation of fruits stood at 6.110 million hectares while vegetables were cultivated at 9.542 million hectares. However, India's share in the global market is still $\sim 1 \%$ only, despite developments in the areas of state-of-the-art cold chain infrastructure and quality assurance measures. Similarly, large part of the northern India suffers from flood. It has adversely affected aquaculture activities as prices slump before onset of floods and fish escapes after ponds are inundated. In Bihar, fish are transported from coastal areas of Andhra Pradesh and Tamilnadu, nearly $1500 \mathrm{kms}$ away. Fruits, vegetables and fishes are consumed mostly where they are produced due to inaccessibility in rural and mountains, bad road condition, unavailability of specialized vehicles, presence of middleman and absence of cost-effective preservation techniques. The sector has failed to realize its economic and employment generation potential.

Brackish water aquaculture (Labeo rohita,Catla catla, etc.) and seasonal horticulture products (eagle marmelos, Emblica officinialis, eugeria jambolana etc.) are sought to be used for increased income generation and food protection [2] by designing appropriate solar dryer. This decade has seen drastic changes in popular perception favouring naturopathy based upon changing food habits and inclusion of medicinal plants/fruits as natural cures of various diseases. Fruits of deserts are natural source known vitamins, useful natural occurring complex chemical compounds, minerals etc., used in long-term treatments of various diseases. Since, deserts and arid 
areas are typical low population density areas; road and rail services are usually non-existent or in bad shape. These are major deterrent in transportation of horticulture products to commercial zones. As, these seasonal fruits mostly decay very fast, prices plunge into seasons and scales new heights otherwise. Fruits of desert and arid regions are of high quality and off- season demand is usually very high. In absence of electric power supply and their inability to absorb expensive and complex preservation technology, it has never aroused popular interest as a major source of economic activities. This has negative impact on production as well as pricing structure. Open sun drying, to some extent, is being practiced since ages. However, it is slow and exposes the produce to various losses and deterioration in quality.

Solar drying is an excellent option for this sector since water content in them varies from $70 \%$ to $90 \%$. Traditional solar drying suffers from serious lacunae including health hazards. Industrial solar drying is not feasible either. This is more so, when oil content of the drying object is high or the outer surface is hard. Examples are, Aonla, Bael and Fish. An advanced standalone cabinet type solar drier uses a combination of 'High Heat Capacity Material' and 'Phase Change Material'. In these systems, high temperature introduces brittleness and low temperature causes increase in drying period. Former has adverse effect on taste and the latter is susceptible to degradation of essential vitamins.

In this paper, solar drier design and process is proposed, which can be used for low temperature fast drying. At first, the system is modelled mathematically and then experimental investigations were carried out to find the time period in which humidity inside the dryer decreases rate of water transport to the surface of the produce. Identification of this critical parameter is used to introduce humidity removal mechanism for a very short period. Low inside dryer humidity allows fast

drying process, while preserving taste and colour to a large extent. The prototype is scaled down unit of large solar dryer. It also allows integration of solar collectors for indirect drying. The results indicate that the family size solar dryer is capable of,

a) Drying fish, prawn, Black berry, Wood apple, Aonla, Laichi and even other similar fruits.

b) The drier keeps away insects without any use of insecticides/pesticides.

c) The food value and medicinal property of the product remains fully intact.

d) The dried products were found acceptable by local people during survey. e) The dried products could be preserved for six months without losing food/medicinal value.

f) The dried products have huge market all over the world.

2 Materials \& MethodNumerical analysis and a series of experiment were undertaken to develop family size solar dryer system for drying aqua product as well horticultural products. Local material use was maximized and the whole construction was kept as simple as possible, so that illiterate masses have no problem in operating them (Fig. 1).

\subsection{Design of solar dryer}

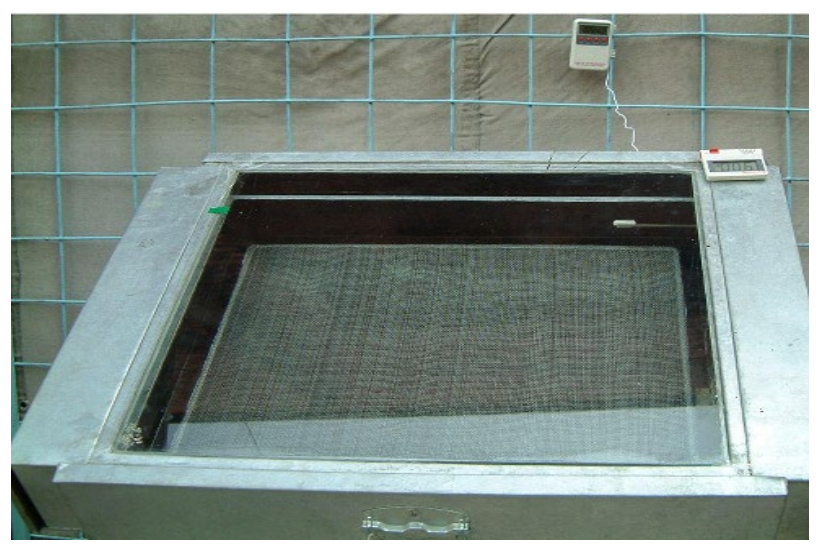

Figure 1: Prototype family size single day extended period state-of-art dryer

Experimental family size solar dryer capable of drying 5 $\mathrm{kg}$ of fish/fruits is designed as follows,

a) Outer box is made of thin Galvanized Iron sheet (size $.65 \mathrm{~m} \times 0.55 \mathrm{~m} \times 0.25 \mathrm{~m})$

b) Inner box is made of Galvanized Iron sheet painted black inside (size $0.6 \mathrm{~m} \times 0.5 \mathrm{~m} \times 0.2 \mathrm{~m}$ )

c) Upper cover is toughened glass, $2 \mathrm{~mm}$ thick.

d) Gap $(5 \mathrm{~cm})$ between the outer and inner boxes is filled with insulating material locally available (rice husk, wooden particles etc.)

e) PCMs and HHHCMs are used to keep the temperature within drying range (For this drier, the volume of $0.6 \times 0.5 \mathrm{mx} 0.12 \mathrm{~m}^{3}$, was occupied by nearly $15 \mathrm{~kg}$ of stone chips to stabilize the temperature in the required range along with $5 \mathrm{kgs}$ of specific $\mathrm{PCMs}$ )

f) Inner box has a perforated tray above the heat capacity material, for holding the fish/fruit

Theoretical basis of design is based upon total heat gain by the system, which is essentially equal to total heat loss from the system in steady state condition. 
Design and Development of Low Temperature Community Solar Dryer for Oily and Hard Edible Produces

$$
(\alpha \tau)_{e f f} I(t) A_{c}=M_{f} C_{f} \frac{d T_{f}}{d t}+U_{s}\left(T_{f}-T_{a}\right)
$$

Where, $(\alpha \tau)_{\text {eff }}$ is product of effective absorptivity and transmittivity, $I(\mathrm{t})$ is solar radiation on the top cover of dryer $\left(\mathrm{W} / \mathrm{m}^{2}\right), T_{\mathrm{f}}$ is fish/fruit temperature $\left({ }^{\circ} \mathrm{C}\right), \mathrm{T}_{\mathrm{a}}$ is ambient air temperature $\left({ }^{\circ} \mathrm{C}\right), M_{\mathrm{f}}$ is mass of fishes/fruits $(\mathrm{kg}), A_{\mathrm{c}}$ is area of dryer receiving solar radiation $\left(\mathrm{m}^{2}\right), C_{\mathrm{f}}$ is specific heat of fish/fruits $\left(\mathrm{J} / \mathrm{Kg}{ }^{\circ} \mathrm{C}\right)$, and $U_{\mathrm{s}}$ is overall heat loss coefficient $\left(\mathrm{W} / \mathrm{m}^{2}{ }^{\circ} \mathrm{C}\right)$ due to temperature difference between inside dryer and ambient. An experimental solar fish dryer was designed on the basis of theoretical modelling for optimum drying time of 6 to 14 hours at a temperature less than $80^{\circ} \mathrm{C}$.

\subsection{Drying experiment}

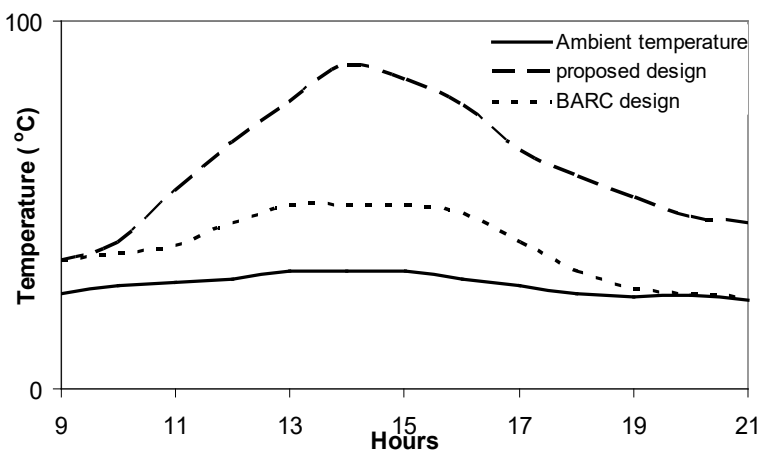

Figure 2: Variation of ambient temperature and inside drier temperature for the proposed design and of dryer design developed by BARC

A series of experiments were conducted to determine drying conditions using incubator in the laboratory. The products (especially brackish water fish) were also subjected to market acceptance. Since drying temperature were kept below $90^{\circ} \mathrm{C}$, essential vitamins, minerals, proteins and other complex compounds can be assumed to be intact. Changes in them, if any, essentially occurs after $100^{\circ} \mathrm{C}[3,4]$. At first, Catla (Catla catla), Rohu (Labeo rohita), Boyari (Wallago, attu) Garai (Channa punctatus) Rewa (Cirrhinus reba) Gaincha (Macrognathus aculeatus) Naini (Cirrhinus mrigala) were experimented. Out of these species, results of drying of Rohu is presented. Thereafter, Wood Apple (Aegle mamelos), Black Berry (Eugeria Jambolana), and Aonla (Emblica officinalis) were tested. Finally, high sugar content Lichi (Litchi chinesis) were also dried to demonstrate the robustness of the dryer. As per available literature, the medicinal properties of two most important desert fruits are as follows,

\subsubsection{Labeo rohita}

Average chemical composition of Rohu is as follows (100 $\mathrm{g}$ of edible portion of raw meat), Moisture - 76.4\%; Protein - 16.6\%; Fat - 1.4\%; CHO- 4.4\%; Energy - 650 kcal; Iron -1\%; Niacin - 0.7\%; Thiamin --- $0.05 \%$; Riboflavin --- $0.07 \%$

\subsubsection{Aegle marmelos:}

Modern use: Fruits: chiefly used in (i) chronic diarrhea and dysentery; (ii) as a good laxative, and the sherbet prepared from the pulp is good for bacillary dysentery; Half-ripe fruit: astringent, digestive and used in diarrhea. It is also antidiuretic, anthelmintic, antipyretic, carminative, tonic.

Chemical contents: Average chemical composition of fruits: water $61.5 \%$, Protein $-1.8 \%$, Fat $-0.3 \%$, Fibres $2.99 \%$, CHO $-31.8 \%$, Cal $85 \mathrm{mg}, \mathrm{Fe}-0.6 \mathrm{mg}$, Thiamine $0.13 \mathrm{mg}$, Riboflavin $-0.3 \mathrm{mg}$, Niacin $-1.1 \mathrm{mg}$, Vitamin C $-8 \mathrm{mg}$, Energy $-137 \mathrm{Kcal}$.

Bark of root and stem: umbelliferone, other coumarins, $\beta$ sitosterol, aurapten, marmin, lupeol, two unidentified alkaloids and two unknown compounds-their proportion varies with the age of the bark; Stem: yields a good gum; Heartwood: a ferro-quinoline alkaloid,/dictamine, marmasin and $\beta$-sitosterol; Leaves: $\gamma$-sitosterol, aegeline, aegelenine, lupeol; sitosterol, rutin, marmesinin, $\beta$ sitosterol, glucoside and essential oil; Fruits: psoralen, aegelinol, furanocoumarin, marmelide, $\beta$-sitosterol and essential oil; Ripe fruits: xanthotoxol, scoparone, scopoletin, umbelliforone, marmesin, skimmin and $\beta$ sitosterol glucoside.

\subsubsection{Emblica officinalis}

Modern use: Fruit: pronounced expectorant, antioxidant, anticancerous; $\mathrm{EtOH}(50 \%)$ extract of fruit: antiviral, carminative, stomachic; Aqueous extract of fruit: increases cardiac glycogen level and decreases serum GOT, GPT and LDH in rats; Fruit-juice: (i) mixed with turmeric powder and honey: cures diabetes insipidus; (ii) in ghee: used for abdominal and glandular tumours; a constituent of the medicine SG-1-Switradilepa used against vitiligo, and of an antibiotic drug Septilin.

Chemical contents: Average chemical composition of fruits: water $81.2 \%$, Protein $-0.5 \%$, CHO $-14 \%$, Fat $0.1 \%$. Root: ellagic acid, oleanolic acid, oleanolic aldehyde, lupeol; Stem-bark: lelucodel-phinidin, procyanidin, 3-0-gallated prodelphinidin and tannin; Stem and Leaf: lupeol, $\beta$-sitosterol; Fruit: vitamin C, carotene, riboflavine, D-glucose, D-fructose, myoinositol, nicotinic acid, D-galacturoniaacid, phyllemblic acid, mucic acid, 
fatty acids, D-arabinosyl, D-xylosyl, L-rhamnosyl, Dglucosyl, D-mannosyl, D-galactosyl.

\subsubsection{Eugeria jambolana}

Modern uses: Fruit is used in dysentery, diabetes, blood complaints. Bark of fruit: astringent and used in sore throat, bronchitis, asthama, ulcer and dysentery.

Chemical composition: Average chemical composition of fruits: Water $-78.2 \%$, Protein $-0.7 \%$, Fat $-0.15 \%$, Carbose - 19\%, Salt - 0.4\%, Calcium - 0.3\%, Phosphorous $-0.6 \%$, Fibres $-0.9 \%$.

\subsubsection{Litchi Chinenses}

Modern use: Anti-oxidant, rich source of Potassium and rich taste. Alcohol brewed from it is high in demand.

Chemical contents: Average chemical composition of fruits: water $81.76 \%$, Protein $-0.83 \%$, $\mathrm{CHO}-16.53 \%$, Fat $-0.44 \%$, Fibre $-1.3 \%$, Sugar $-15.23 \%, \mathrm{Mg}-10 \mathrm{mg}$, $\mathrm{P}-31 \mathrm{mg}, \mathrm{K}-171 \mathrm{mg}$, Vit. C $-71.5 \mathrm{mg}$, Vit. E - 0.07 $\mathrm{mg}$.

\section{Results and Discussion:}

Large variation in climatic parameters made it difficult to stabilize inside temperature of the dryer. Therefore, two arrangements were made, (a) high heat capacity materials were used in ample to offset any change in climatic parameters and perforated controlled opening to control high temperature inside. On a typical day, Fig. 2, shows the Variation of ambient temperature and inside drier temperature for the proposed design for which temperature can be stabilized in the range from $45^{\circ} \mathrm{C}$ to $90^{\circ} \mathrm{C}$. Temperature and duration of drying can be traded off. It is compared with fish dryer design of BARC [5], which can dry $15 \mathrm{~kg}$ of fish as compared to the proposed dryer, which has a capacity of $5 \mathrm{~kg}$.

However, the former takes three days as compared to one day required by the proposed design. Besides, it removes uncertainty in climatic parameters and can be used when it is a clear day. Even a half clear day can be enough in many drying cases. If the temperature crosses the designated highest temperature of drying, the system can be insulated/covered to stop further heat gain as has been done in case of fish drying experiments. Figure 3 shows typical results of drying for Labeo rohita. Initial weights of the fish does influence the drying time as shown in Fig. 3 . These dried fishes were preserved in white polythene zip bags for over eight months and tested for nutrition content, which remained intact. Average weight of the dried fish become less than $30 \%$ of its original weight. No freezing carrier is required for its transportation.

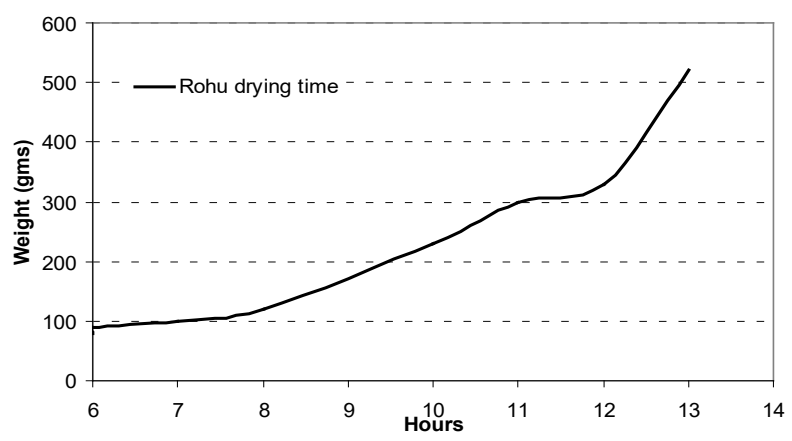

Figure 3: Variation of drying time for Rohu (Labeo rohita) with weight

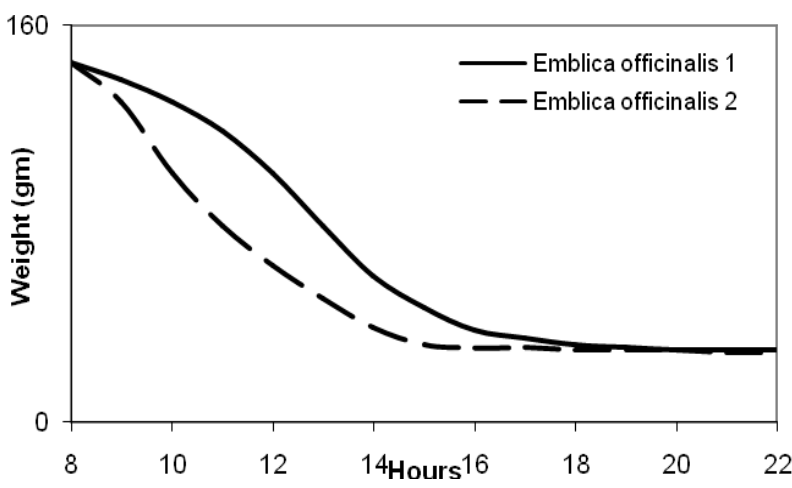

Figure 4: Variation of dried weight with time of Aonla without humidifier (Emblica Officinalis1) and with humidifier (Emblica Officinalis 2

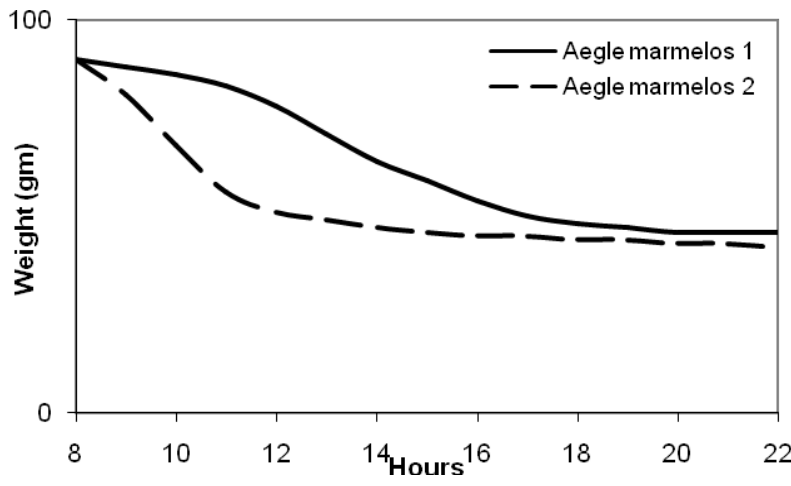

Figure 5: Variation of dried weight with time of wood apple without humidifier (Aegle mamelos1) and with humidifier (Aegle mamelos2)

Figure 4-7 shows the drying results of Aonla (Emblica officinalis), Wood Apple (Aegle mamelos), Jamun (Eugeria jambolana1), and high sugar content Lichi (Litchi chinesis). Results indicate that drying time decreases sharply if dehumidifier mechanism is used. Emblica officinalis had dried weight of $20 \%$ and average drying time 7-10 hours. Aegle mamelos dried weight was approximately 50\% and drying time was 7-11 hours. 
Eugeria jambolana had dried weight of $\sim 43 \%$ and drying time, 7-10 hours. However, Litchi chinesishad dried weight $\sim 30 \%$, while average drying time, 12 HRS in both cases. It indicates that sugar content is a very important factor in drying process and this dryer is not quite suitable for drying high sugar content fruits.

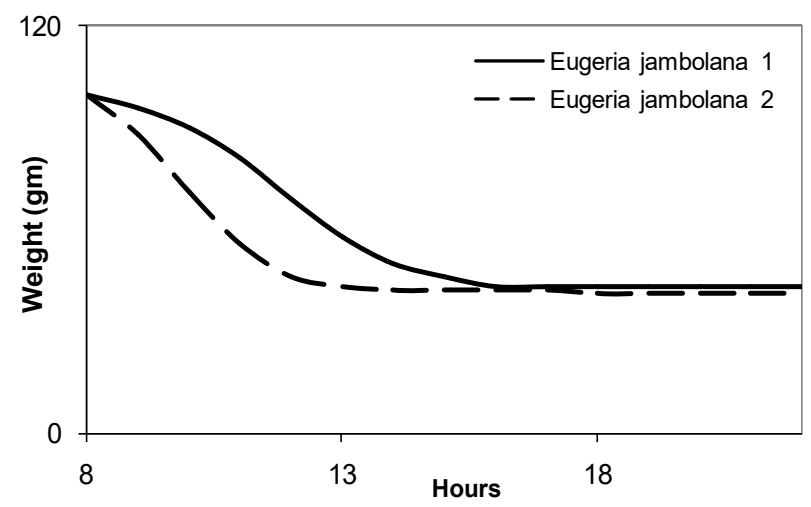

Figure 6: Variation of dried weight with time of Jamun without humidifier (Eugeria jambolana1) and with humidifier (Eugeria jambolana 2)

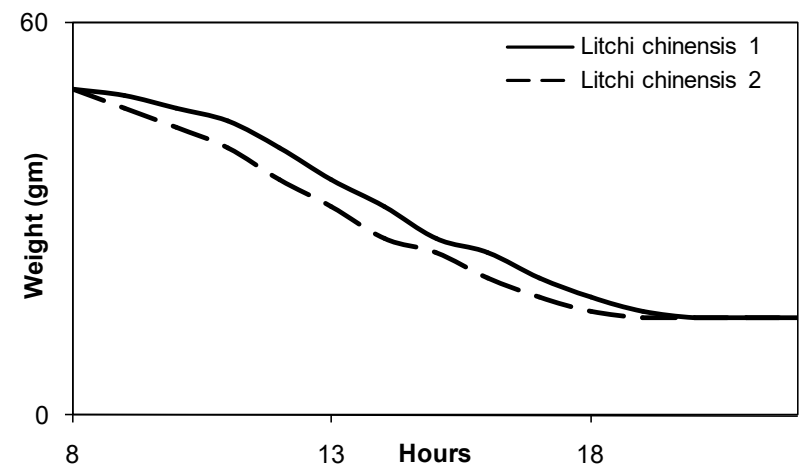

Figure 7: Variation of dried weight with time of Litchi without humidifier (Litchi Chinesis1) and with humidifier (Litchi Chinesis2)

\section{Conclusion}

Solar fish/fruit drying can play a vital role in economic development of rural and remote areas. It would not only stop migration of people to mega cities, but also help in preserving ecological balance and nutrition, without fear of harsh climatic condition at regional level.

\section{References}

[1] Sinha S, Sanjay Kumar, Gyan S and Kojima T (2004), Integrated resource management and renewable energy base modelling to reduce environmental stress, promote conservation and stop mass migration to urban slums from a semi-arid village. J. of Arid Land Studies, 14S:97-100.

[2] Choudhary Shilpa, Baby Pallavi, Sinha S and Sanjay Kumar (2005), Trans-boundary floods induced by global climate change: development of solar fish drying technology to combat food deficit in seasonally inundated northern India. J. of Agricultural Meteorology, 60(5):481484.

[3] Moorjani, MN (1984), Fish Processing in India, ICAR, N. Delhi.

[4] Shammi QJ and Bhatnagar S (2002), App. fisheries, Agrobios, Jodhpur, India.

[5] Pravin Sapkale, Basu S., Warrier SB. (2003): Storage characteristics of solar-dried Indian Mackerel. J. of the Indian Fishery Association, 30:165-171.

[6] DNE-1 (2017), Nutrition for the Community, Practical Manual, Indira Gandhi Open University Publication, N. Delhi, India 